\title{
Renal Prostaglandin Synthesis in the Spontaneously
}

\section{Hypertensive Rat}

\author{
Michael J. Dunn with the technical assistance of Douglas Howe and \\ MarietTa Harrison
}

From the Division of Nephrology, Department of Medicine, University of Vermont, Burlington, Vermont 05401

\begin{abstract}
A в S T RACT The precise role of the kidney in spontaneous experimental hypertension is unknown. We have analyzed the rates of renal prostaglandin synthesis by utilizing a spontaneously hypertensive rat model. The synthetic rate of prostaglandin $E_{2}$, prostaglandin $F_{2 \alpha}$, and prostaglandin $\mathrm{A}_{2}$-like products was measured in vitro with renal microsomes. In the rabbit and rat there is a steep gradient of microsomal prostaglandin synthetase from papilla to cortex with highest activities in the papilla. Comparison of the activity of prostaglandin synthetase in medullary microsomes from normotensive and hypertensive rats showed accelerated synthesis in the spontaneously hypertensive rat. These differences appeared after several months of age, were statistically significant from 3 mo of age and, on the average, represented at least a twofold increase of in vitro activity.
\end{abstract}

All classes of prostaglandins were involved with increased synthesis of prostaglandin $\mathrm{E}_{2}$, prostaglandin $\mathrm{F}_{2 \alpha}$, and prostaglandin $\mathrm{A}_{2}$-like material. These data reenforce and extend previous work showing alterations of granularity and presumably prostaglandin synthesis in renal medullary interstitial cells in various experimental hypertensions.

We also measured renal tissue content of prostaglandin $\mathrm{E}$ and prostaglandin A-prostaglandin B by radioimmunoassay. Swift and careful handling of the tissue was necessary to avoid extensive postmortem synthesis of prostaglandins. In rapidly-frozen medullary tissue only prostaglandin $\mathrm{E}$ was detectable in concentrations ranging from 10 to $200 \mathrm{pg} / \mathrm{mg}$ tissue. No significant differences were found in the medullary content of

Presented at the second U.S.-Japan seminar on the spontaneously hypertensive rat, April 1976, Newport Beach, Calif.

Received for publication 29 December 1975 and in revised form 14 June 1976. prostaglandin $\mathrm{E}$ in the control and hypertensive rats despite the increased rates of enzymatic synthesis.

We conclude that renal prostaglandin synthesis is increased in renal medullary microsomes obtained from spontaneously hypertensive rat. This apparently occurs in response to the progressive development of hypertension since young animals did not show an increase. Renal tissue prostaglandin $\mathrm{E}$ content did not increase and therefore appears to be a poor index of enhanced prostaglandin synthesis.

\section{INTRODUCTION}

There is a growing awareness and interest in the vasodepressor role of the kidney $(1-4)$. The compounds which seem most likely to be mediators of an antihypertensive function are the renal medullary prostaglandins and a neutral lipid discovered by Muirhead (1). Considerably more is known about the renal prostaglandins, although their importance in physiologic situations is unknown. Whereas some authors have speculated that renal prostaglandin deficiency may cause hypertension, others have concluded that enhanced prostaglandin production may occur in response to hypertension (3). The major renal prostaglandin which could serve an antihypertensive function is prostaglandin $\mathrm{E}_{2}\left(\mathrm{PGE}_{2}\right)^{1}$ since it is vasodilatory and natriuretic in most species (2). Although $\mathrm{PGA}_{2}$ also shares these pharmocologic properties (4), there is considerable disagreement about the physiologic importance and biochemical origin of $\mathrm{PGA}_{2}(5,6)$. Previous publications have asserted that renal prostaglandin secretion increases in experimental hypertension (3,

${ }^{1}$ Abbrciations used in this paper: PGA, prostaglandin A ; $\mathrm{PGB}$, prostaglandin $\mathrm{B}$; PGE, prostaglandin $\mathrm{E}$; SHR, spontaneously hypertensive rat; TLC, thin-layer chromatography; WKy, Wistar Kyoto control. 
7-9) or contrariwise that prostaglandin production by the kidney decreases in hypertension (10-12). Although these authors have utilized many different experimental models, the more important problem has been the complexity and diversity of the methodologies for the measurement of prostaglandin levels. Additionally since tissue content of prostaglandins may not accurately reflect in vivo synthetic rates, it becomes imperative to assess rates of synthesis as well as tissue levels.

The objective of the present experiments were threefold: (a) To utilize the spontaneously hypertensive rat (SHR) of Okamoto since it is a well-studied model of essential hypertension not requiring any manipulations of renal vessels or parenchyma; $(b)$ To measure prostaglandin synthesis in vitro by using renal medullary microsomes and a controlled radiochemical assay; (c) To measure renal prostaglandin content by radioimmunoassay, taking care to minimize postmortem prostaglandin synthesis in the tissue.

As a result of these experiments we conclude that renal medullary prostaglandin synthesis $\left(\mathrm{PGE}_{2}\right.$ and $\mathrm{PGF}_{2 \alpha}$ ) increases substantially as hypertension develops in the SHR.

\section{METHODS}

Animals. The rats were obtained from the University of Vermont Colony of Wistar Kyoto control (WKy) and SHR. This colony has been inbred with brother-sister matings from original breeding stock obtained from $\mathrm{Dr}$. Carl Hansen, Chief, Genetics Unit, Animal Production Section, National Institutes of Health. This stock was originally derived from Okamoto-Aoki stock from Kyoto, Japan. There were very few spontaneous deaths in the SHR between $1 \mathrm{mo}$ and $1 \mathrm{yr}$ of age, and the occasional death which occurred was due to respiratory infections which also affected the WKy. Systolic blood pressures were recorded by tail cuff sphygmomanometry after warming the animal. Ten recordings were made and the mean of the last five pressures (systolic) were used. Pressures were recorded monthly beginning at $6 \mathrm{wk}$ of age. The rats were sacrificed by decapitation. For the assay of prostaglandin synthetase the kidneys were decapsulated, cut in half sagitally, and the medulla (including papilla) of each was dissected out. The medullae from both kidneys of a single rat were paired and treated experimentally as a single sample for the synthetase assay. The wet weights of the medullae were $293 \pm 18 \mathrm{mg}$ (mean \pm SEM) for WKy and $262 \pm 14 \mathrm{mg}$ for SHR. The yield of microsomal protein from each $\mathrm{mg}$ of renal medulla was similar in WKy and SHR and was 0.47 and $0.42 \%$, respectively. The tissue was chilled at all times after sacrifice of the animal. Experiments were always done by pairing a WKy and SHR of similar age for sacrifice on the same day. The animals were not paired by sex.

For the analysis of tissue prostaglandin content one kidney was rapidly removed, cut sagitally, the medulla dissected and plunged into liquid nitrogen within $1 \mathrm{~min}$ of sacrifice. The contralateral kidney was dissected similarly and the fresh medulla was maintained on ice for $30 \mathrm{~min}$ before extraction. Initial experiments showed that freezing the entire kidney and dissection of the medulla on dry ice, which is difficult, yielded PGE concentrations similar to those obtained by freezing the medulla after dissection.

Tissue extraction. The medullary tissue for the synthetase assay was minced with a razor blade, placed in $3-\mathrm{ml}$ of $0.05 \mathrm{M}$ Tris, $\mathrm{pH} 8.0$ buffer in a Potter-Elvehejn homogenizer, and homogenized briefly. The homogenate was centrifuged at $10,000 \mathrm{~g}$ for $10 \mathrm{~min}$ at $4^{\circ} \mathrm{C}$, the supernate was removed and recentrifuged at $110,000 \mathrm{~g}$ for $1 \mathrm{~h}$ at $4^{\circ} \mathrm{C}$. The pellet containing the microsomes of renal medulla was resuspended in $1.0 \mathrm{ml}$ of $0.05 \mathrm{M}$ Tris $\mathrm{pH} 8.0$, frozen overnight, and utilized the following day. The supernatant solution, from the ultracentrifugation, was boiled, recentrifuged briefly at $10,000 \mathrm{~g}$, and used in the assay (13).

Tissue for prostaglandin radioimmunoassay was placed in $3 \mathrm{ml}$ methanol: water $(2: 1)$ with indomethacin $5 \mu \mathrm{g} / \mathrm{ml}$ and $1,000 \mathrm{cpm} \mathrm{H}^{3} \mathrm{PGE}$ (tracer for calculation of recoveries). Homogenization was done with a Potter-Elvehejm apparatus. The homogenate was acidified to $\mathrm{pH} 3.5$ with $0.1 \mathrm{M} \mathrm{HCl}$ and extracted twice with $4 \mathrm{ml}$ chloroform. The organic extract was evaporated under nitrogen and the residue was resolubilized in benzene: ethylacetate: methanol, $60: 40: 2$, and applied to silicic acid columns (see below).

Synthetase assay. The radiochemical assay of renal microsomal prostaglandin synthetase was done by using $\left[{ }^{14} \mathrm{C}\right]$ arachidonic acid as substrate and thin-layer chromotography for separation of end products (14). The reaction mixture of $2 \mathrm{ml}$ contained: microsomal suspension $0.4 \mathrm{ml}$, $\left[{ }^{14} \mathrm{C}\right.$ ]arachidonic acid $0.1 \mu \mathrm{Ci}$ (Amersham/Searle Corp., Arlington Heights, Ill., sp act $58 \mathrm{mCi} / \mathrm{mmol}$ ), unlabeled arachidonic acid $1 \mu \mathrm{M}$ (Sigma Chemical Co., St. Louis, Mo.), boiled supernate from the microsomal spin $1.0 \mathrm{ml}$, glutathione $2 \mathrm{mM}$, epinephrine $2.5 \mathrm{mM}$, hemoglobin $1 \mu \mathrm{M}$, and $0.4 \mathrm{ml}$ of Tris buffer $\mathrm{pH} 8.0,0.05 \mathrm{M}(14,15)$. Controls were run for each experiment with either boiled microsomes or $0.4 \mathrm{ml}$ Tris buffer. Both yielded similar results with less than $3 \%$ nonenzymatic conversion of arachidonic acid to other products. Measured consumption of arachidonic acid substrate did not exceed $40 \%$ and usually was $15-25 \%$ with rat renal microsomes. The microsomal protein concentration in the reaction media was $0.5-1.0 \mathrm{mg} / \mathrm{ml}$ and was always comparable for WKy controls and the SHR.

The microsomes were incubated at $38^{\circ} \mathrm{C}$ for $15 \mathrm{~min}$ in a shakerbath. The reaction was stopped by placing the flasks in ice and adding $15 \mathrm{ml}$ of chloroform-methanol, 2:1. Approximately $5 \mathrm{mg}$ of unlabeled carrier $\mathrm{PGA}_{2}, \mathrm{PGE}_{2}$, and $\mathrm{PGF}_{2}$ were added to each flask to facilitate the separation and identification of the labeled end products.

Extraction and chromatography. The reaction vessels were extracted with the chloroform-methanol for $30 \mathrm{~min}$ at room temperature. The samples were then filtered (Whatman no. 1) into $125 \mathrm{ml}$ separatory funnels and the flasks and filters were rinsed twice with $3 \mathrm{ml}$ of chloroform-methanol 2:1. The filtrate was acidified with $4 \mathrm{ml}$ of $0.03 \mathrm{M} \mathrm{HCl}$ and shaken vigorously for extraction of the prostaglandins. The aqueous layer was discarded and the organic layer was washed once with $5 \mathrm{ml}$ of distilled water. The organic phase was evaporated under nitrogen and resuspended in $100 \mu \mathrm{l}$ of chloroform-methanol, $1: 1$, for chromatography. Thin-layer chromatography was done by using silica gel, $20 \times 20 \mathrm{~cm}$ precoated plastic sheets (Brinkmann Sil-G-Hy, Brinkmann Instruments, Inc., Westbury, N. Y.). The plates were spotted with $25 \mu \mathrm{l}$ of the extracted end products and with appropriate standards ( $\mathrm{PGA}_{2}, \mathrm{PGE}_{2}$, and $\mathrm{PGF}_{2 a}$ were always used whereas $\mathrm{PGB}_{2}$ and $\mathrm{PGD}_{2}$ were occasionally utilized as additional standards). The plates were developed to $15 \mathrm{~cm}$ in a chloroform, methanol, 
TABLE I

Levels of PGE in Rat Renal Medulla

\begin{tabular}{lcllrr}
\hline & \multicolumn{2}{c}{ Frozen samples* } & & \multicolumn{2}{c}{ Fresh samples } \\
\cline { 2 - 3 } \cline { 5 - 6 } Age & WKy (6) 8 & SHR (6) & & WKy (6) & \multicolumn{1}{c}{ SHR (6) } \\
\hline$m o$ & & pg/mg tissue, & mean $\pm S E M$ & \\
2 & $149 \pm 38$ & $63 \pm 16$ & & $455 \pm 22$ & $330 \pm 72$ \\
$4-5$ & $60 \pm 25$ & $33 \pm 18$ & & $106 \pm 25$ & $90 \pm 22$ \\
9 & $16 \pm 5$ & $36 \pm 15$ & & $190 \pm 84$ & $128 \pm 27$ \\
18 & $60 \pm 26$ & $14 \pm 4$ & & $207 \pm 59$ & $111 \pm 68$ \\
\hline
\end{tabular}

* Frozen in liquid nitrogen within $60 \mathrm{~s}$ of slaughter.

† Contralateral kidney kept at $4^{\circ} \mathrm{C}$, on ice, for $30 \mathrm{~min}$.

8 Systolic blood pressure for the four ages respectively: $153 \pm 4,123 \pm 4,131 \pm 6$, and $123 \pm 3 \mathrm{~mm} \mathrm{Hg}$, mean $\pm \mathrm{SEM}$

The 2-mo values may be artifactually high due to the small size of the tail.

$\| n=6$ at each age. Systolic blood pressure for the four ages respectively was: $175 \pm 4,194 \pm 4,209 \pm 8$, and $186 \pm 5 \mathrm{~mm} \mathrm{Hg}$, mean $\pm \mathrm{SEM}$.

glacial acetic acid, and water system $90: 8.5: 1.0: 0.65$. The plates were air-dried and stained with $\mathrm{I}_{2}$ vapor. The areas corresponding to prostaglandin standards $\left(\mathrm{PGA}_{2}, \mathrm{PGE}_{2}\right.$, and $\mathrm{PGF}_{s_{a}}$ ) were circled, cut, and placed in $3 \mathrm{ml}$ of Omnifluor ( $4 \mathrm{~g}$ per liter toluene) for liquid scintillation counting. The $R_{t}$ values were: $P_{G F} 0.20, P G E_{2 a} 0.33$, and $\mathrm{PGA}_{2}$ 0.66. Areas not corresponding to our prostaglandin standards were also cut and counted. Autoradiography was often done on a second thin-layer chromatography (TLC) plate as a qualitative assessment of the TLC patterns.

Calculations. From the counts obtained in the experimental samples we subtracted the counts on the corresponding portion of the TLC plate which served as the control (no microsomes or boiled microsomes). After correction for dilution, the amount of prostaglandin synthesized was calculated on the basis of the specific activity of the arachidonic acid in the reaction mixture. PG synthesized = radioactivity in PG's (cpm) divided by initial specific activity of arachidonic acid (cpm/pmol). The amount of protein in the microsomal suspension was determined (16). No analysis was done of the percent recovery of added prostaglandins. Results are expressed as picamoles of prostaglandin synthesized/15 min per $\mathrm{mg}$ of microsomal protein.

Prostaglandin radioimmunoassay. The details of this methodology are presented elsewhere (17). We have generally followed the methodology of Jaffe and Behrman (18) In brief we separated the classes of prostaglandins on silicic acid chromatographic columns. We have obtained excellent separation of PGA and PGB from PGE through elution with benzene: ethylacetate $(60: 40)$ for the $A$ and B prostaglandins and with benezene: ethylacetate: methanol $(60: 40: 4)$ for the $E$ prostaglandins. These two fractions were collected separately, dried under nitrogen, and converted to $\mathrm{PGB}$ in methanolic potassium hydroxide $\mathrm{pH} 13$ for $40 \mathrm{~min}$. The sample was reacidified with formic acid, reextracted in $6 \mathrm{ml}$ chloroform: $\mathrm{H}_{2} \mathrm{O}(2: 1)$, redried under nitrogen and finally solubilized for radioimmunoassay in 1 $\mathrm{ml}$ of Tris-isogelatin buffer $\mathrm{pH}$ 7.4. All PGE values were corrected for recovery of the added $\mathrm{H}^{3} \mathrm{PGE}$ and recoveries varied from 50 to $80 \%$.
The radioimmunoassay utilized antibodies to $\mathrm{PGB}_{1}$ (Clinical Assays Inc., Cambridge, Mass.), $\mathrm{H}^{3} \mathrm{PGB}_{1}$, and cold $\mathrm{PGB}_{1}$. After $1 \mathrm{~h}$ incubation at $37^{\circ} \mathrm{C}, 1 \mathrm{ml}$ of dextran coated charcoal, $12 \mathrm{mg} / \mathrm{ml}$, was added for $3 \mathrm{~min}$ followed by centrifugation to separate bound and free PGB. The supernatant fraction was counted in a liquid scintillation spectrometer. A column blank composed of solvents without tissue was run for every experiment and the value (always less than $30 \mathrm{pg}$ PGB) subtracted from all tissue concentrations. The sensitivity of the standard curve was $50 \%$ displacement at $200 \mathrm{pg}$ of PGB and detection limits varied between 15 and $30 \mathrm{pg}$. These methods cannot differentiate between PGA and PGB in the original sample. No attempt was made to discriminate between $\mathrm{PGE}_{1}$ and $\mathrm{PGE}_{2}$ and therefore the values for PGE in Table I are reported without designation of the unsaturation of the side chain. Since the kidney predominantly synthesizes $\mathrm{PGE}_{2}$ it is probable that most or all of the measured PGE was $\mathrm{PGE}_{2}$. Proof that we were indeed measuring prostaglandins and not nonspecific binding of other substances is presented elsewhere; namely that indomethacin in vivo reduced tissue levels $75 \%$ and that indomethacin or meclofenamate reduced renal medually cell culture production of PGE by $90 \%$ (17) as measured by this radioimmunoassay.

Statistics. We utilized nonparametric and nonpaired analyses, namely the Mann-Whitney $U$ test. Although the experiments were paired for age and day of sacrifice and assay, they were not paired by sex. The differences observed for PG synthetase gained even greater significance with a paired analysis (Wilcoxon matched-pairs signedranks test), whereas the differences observed in prostaglandin content of tissue were not significantly different with either paired or nonpaired analysis.

\section{RESULTS}

The TLC system. Fig. 1 shows the separation of the various prostaglandins on our TLC system. The migration pattern of the unlabeled standards, as determined from iodine staining, is superimposed on the autoradiograph for comparison. There is clearcut separation of $\mathrm{PGF}_{2 \alpha}$ and $\mathrm{PGE}_{2}$. The labeled end product which comigrates with the PGA. standard may be 15 keto-dihydro $\mathrm{PGE}_{2}$ or hydroxy acids rather than authentic $\mathrm{PGA}_{2}$ (see Discussion). It is also apparent that indomethacin, $5 \mu \mathrm{g} / \mathrm{ml}$, significantly reduced synthetase activity on the autoradiogram. By using rabbit medulla, indomethacin or meclofenamate $5 \mu \mathrm{g} / \mathrm{ml}$, inhibited 93 to $99 \%$ of synthetase activity in vitro.

Distribution of prostaglandin synthetase. We evaluated the distribution of prostaglandin synthetase in the rat and rabbit kidney. In agreement with other workers (19), we found a preponderance of prostaglandin synthetase in the papilla with a decreasing amount proceeding through medulla to cortex. The ratio of synthetase activity $\left(E_{2}\right.$ and $\left.F_{2 \alpha}\right)$ between papilla and cortex was approximately 100 to 1 . It was also noted that the activity of prostaglandin synthetase was greater in the rabbit especially in the deeper zones of the kidney. In subsequent studies of hypertensive rats and their controls, we utilized the medulla and papilla for micro- 


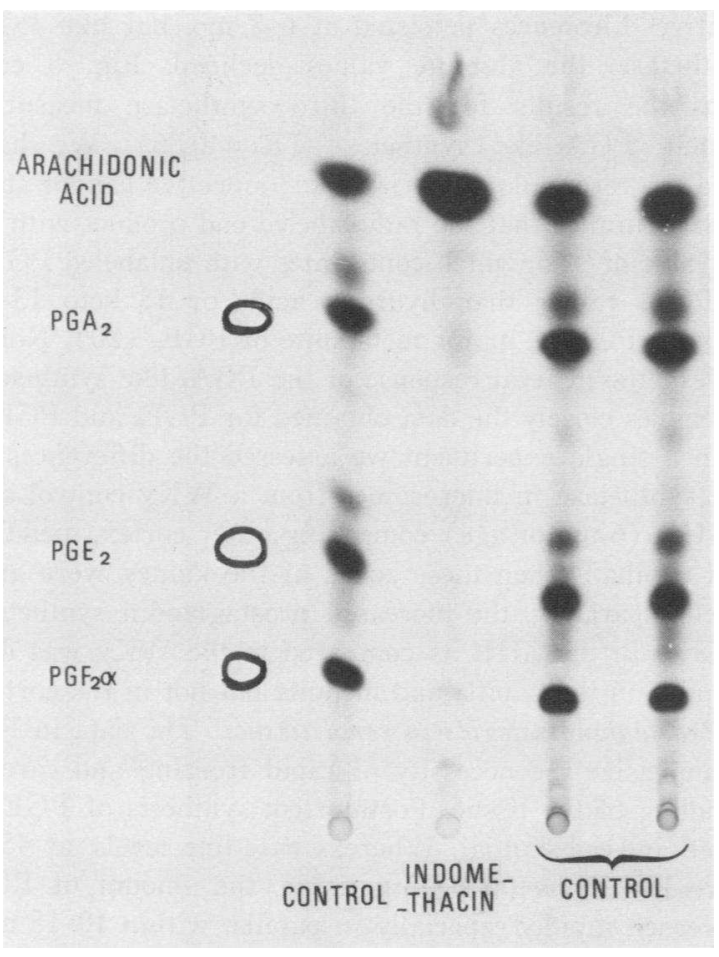

FIGURE 1 TLC of the prostaglandin standards and autoradiography of the labeled end-products of the microsomal incubation. These results, obtained with rabbit medullary microsomes, were identical to those obtained with rat microsomes. The greater activity of the rabbit synthetase however produced clearer autoradiographs. The migration pattern of the standards $\left(\mathrm{PGF}_{2 a}, \mathrm{PGE}_{2}\right.$, and $\left.\mathrm{PGA}_{2}\right)$ obtained from the TLC plate has been superimposed to the left of the autoradiographic plate. The prostaglandin which migrates just in front of $\mathrm{PGE}_{2}$ is probably $\mathrm{PGD}_{2}$. Control = rabbit medullary microsomes; indomethacin $=$ microsomes and $5 \mu \mathrm{g} / \mathrm{ml}$ indomethacin.

somes since papillary weight alone of a single rat was less than $100 \mathrm{mg}$.

Prostaglandin synthctase in hypertensive rats. Fig. 2 presents the results of preliminary experiments which assessed the kinetics of the prostaglandin synthetase over time and compared prostaglandin synthetase activities in renal medullary microsomes from SHR and WKy rats. Renal medullary microsomes from the hypertensive animals showed a substantially greater activity of prostaglandin synthetase at all points in time. All subsequent experiments used a 15 -min incubation time and results are always expressed as pmole of prostaglandin synthesized/15 min per mg microsomal protein. ${ }^{2}$ These

2 The weights of the fresh medullae were similar in the WKy $(293 \pm 18 \mathrm{mg})$ and the SHR $(262 \pm 14 \mathrm{mg})$. If the activity of the prostaglandin synthetase was expressed per milligram of medullary weight the differences between WKy and SHR would be increased, albeit slightly. Also, the microsomal yields are similar between the two groups of rats, $0.47 \%$ for WKy and $0.42 \%$ for SHR. Since medul-

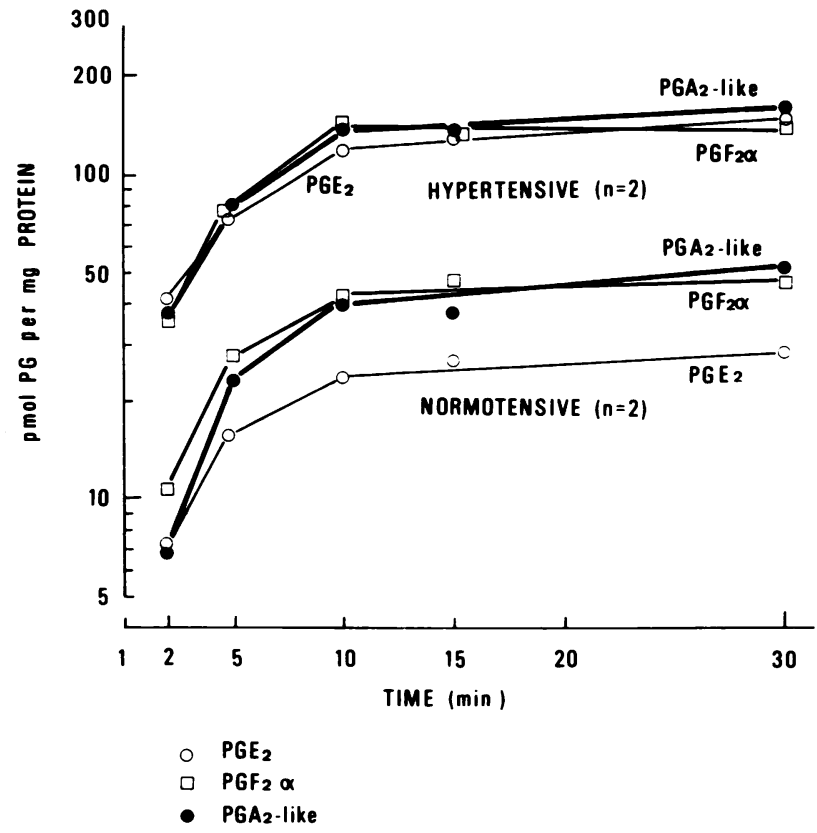

Figure 2 Time study of renal medullary microsomal prostaglandin synthetase. The results from two hypertensive SHR and two normotensive WKy control rats were grouped. It is apparent that the reaction rapidly reaches equilibrium. The differences in activity of prostaglandin synthetase are apparent regardless of the time of sampling. The animals were $5-5 \frac{1}{2}$ mo of age.

data are summarized in Figs. 3, 4, and 5. In Fig. 3 we have depicted the values of $\mathrm{PGE}_{2}$ synthetase for normotensive and hypertensive rats at five different ages. The animals 1 mo of age do not have established hypertension and blood pressure does not stabilize until approximately 6 mo of age (unpublished observation). Whereas PGE synthesis is similiar between WKy and SHR at $1 \mathrm{mo}$, a progressive disparity develops as the animal ages and the hypertension becomes established. The greater synthesis of $\mathrm{PGE}_{2}$ in the SHR compared to $\mathrm{WKy}$ is statistically significant at $3-3 \frac{1}{2}, 4-5$, and $6-7$ mo of age. The systolic blood pressures at $2,3-3 \frac{1}{2}, 4-5$, and 6-7 mo of the SHR (mean \pm SEM) were: $175 \pm 5$, $174 \pm 10,182 \pm 7$, and $196 \pm 12 \mathrm{~mm} \mathrm{Hg}$, respectively; WKy pressures at the same ages were: $130 \pm 3,154 \pm 6$, $123 \pm 4$, and $141 \pm 6 \mathrm{~mm} \mathrm{Hg}$. respectively. The apparent decline of synthetase activity may be artifactual in both normotensive and hypertensive rats at $6-7$ mo of age since these determinations were done within the same

lary weights were similar and microsomal yields were similar, it seems quite unlikely that our results are artifactual and due to some alteration in the renal density of microsomal protein in SHR renal medulla.

${ }^{3}$ We could not accurately measure blood pressure by the tail cuff method in 1-mo animals because of their size. Direct arterial measurements by Simpson show only 10 $\mathrm{mm} \mathrm{Hg}$ difference at this age (52). 


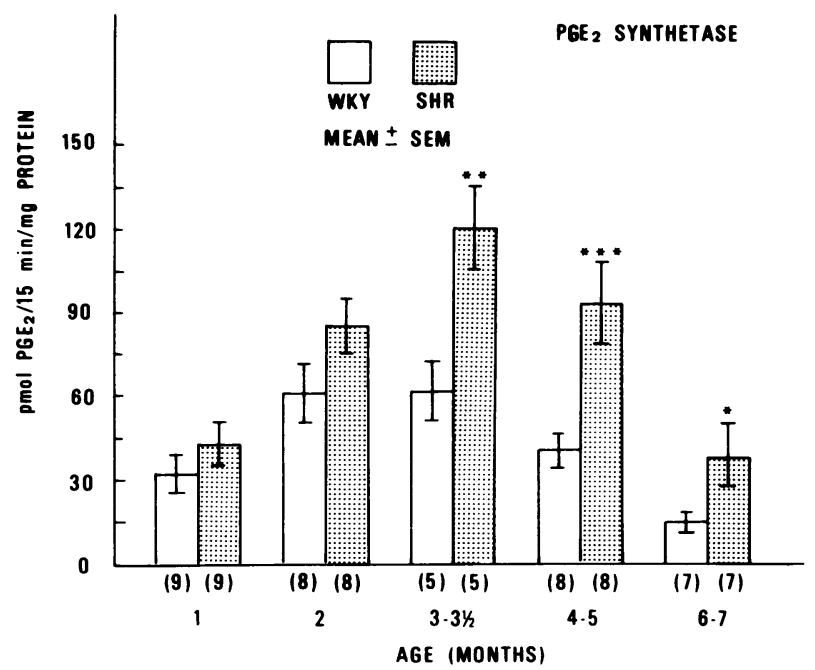

Figure 3 Renal medullary $\mathrm{PGE}_{2}$ synthetase in WKy and SHR at five different ages. The ordinate depicts the pmol of $\mathrm{PGE}_{2}$ synthesized in vitro during a 15 -min incubation. The values are expressed per milligram of microsomal protein derived from renal medulla (including papilla). Results are given as the mean $\pm S E M$ and the number of animals studied is indicated. All animals were paired by age and day of experiment, but not by sex. The age at the time of sacrifice is indicated in months. Statistical analyses, comparing WKy and SHR of the same ages, were done with the Mann-Whitney $U$ test; $*=P<0.05 ; * *=P<0.02$; $* * *=P<0.01$. The apparent decline of synthetase activity in both species at 6-7 mo may be artifactual (see text).

4-wk period, and in several experiments the microsomes were frozen for several days rather than overnight. The results for $\mathrm{PGF}_{2 \alpha}$ synthetase are shown in Fig. 4 and the pattern closely resembles the results with $\mathrm{PGE}_{2}$ synthetase. The hypertensive rats showed a progressive in-

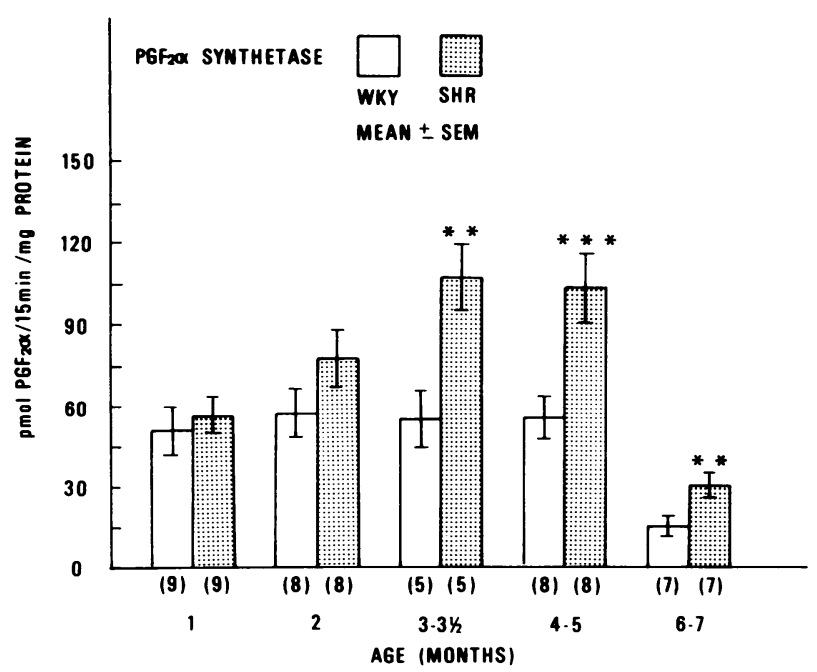

Figure 4 Renal medullary $\mathrm{PGF}_{2 a}$ synthetase in WKy and SHR at five different ages. Refer to legend for Fig. 3 for details. crement of $\mathrm{PGF}_{2 \alpha}$ synthetase up to 4-5 mo of age. The relative differences persisted at $6-7$ mo, but like $\mathrm{PGE}_{2}$ synthetase, the absolute values declined. Fig. 5 contains the results for the third synthetase measured, namely PGAg-like synthetase $\left(R_{t}=0.66\right)$. We have used the terminology "PGA2-like" since we cannot state with assurance that the radiolabeled end product with an $R_{\mathfrak{r}}$ value of 0.66 , which comigrates with unlabeled PGA2, is $\mathrm{PGA}_{2}$ rather than hydroxy acids or 15 keto $13-14$ dihydro $\mathrm{PGE}_{2}$, a major metabolite of $\mathrm{PGE}_{2}$ (20). Nonetheless, the general response of the PGA2-like synthetase resembles closely the data obtained for $\mathrm{PGE}_{2}$ and $\mathrm{PGF}_{2 \alpha}$.

In a single experiment we assessed the differences of PG synthetase in microsomes from a WKy control and a SHR (6 mo of age) comparing outer cortex, medulla, and papilla. When these zones of the kidney were analyzed separately, the increased prostaglandin synthetase activity in the SHR as compared to the WKy was discernible in the papilla and medulla but not in the cortex.

Prostaglandin levels in renal tissue. The data in Fig. 6 emphasize the necessity of rapid freezing and careful handling of the tissue. Postmortem synthesis of PGE is rapid and substantial. Whereas base-line levels, at $45 \mathrm{~s}$, were less than $100 \mathrm{pg} / \mathrm{mg}$ tissue, the amount of PGE increased rapidly especially in papilla, within 10-15 min after decapitation of the rat. The amounts of PGA (including $\mathrm{PGB}$ ) were considerably less at all points of time. Because of these results we froze tissue samples in liquid nitrogen within $60 \mathrm{~s}$ of slaughter and homogenized the tissue in solvents containing indomethacin. For comparison we also analyzed tissue kept on ice for $30 \mathrm{~min}$ after slaughter (subsequently called "fresh"). Table I summarizes these data for renal medullae (including papillae) of six WKy rats and six SHR sacri-

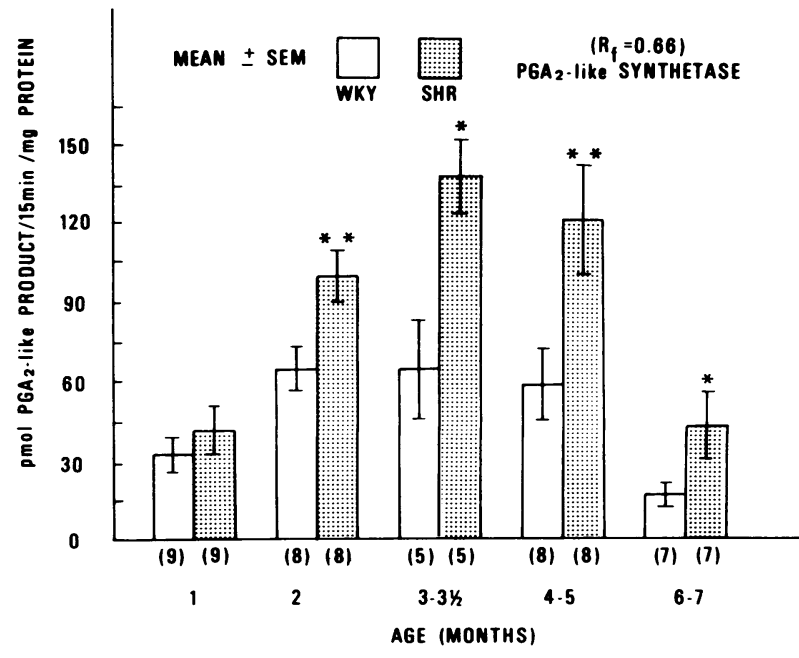

FIgURE 5 Renal medullary $\mathrm{PGA}_{2}$-like synthetase in WKy and SHR. Refer to legend for Fig. 3 for details. A discussion of the terminology "PGA-like" can be found in the text. 
ficed at each of four different ages. The data presented are only for PGE since PGA determinations in 28 renal medullae were never distinguishable from zero. There are no significant differences between the PGE values whether analyzed in a nonpaired or paired fashion in normotensive and hypertensive renal medullae. Likewise there are no significant differences between WKy and SHR when the "fresh" medullae were analyzed. "Fresh" PGE levels were always higher than "frozen" concentrations, as was predicted by the aforementioned studies (Fig. 6). The "fresh" tissue was iced $\left( \pm 4^{\circ} \mathrm{C}\right)$, and hence showed lower PGE content than the tissue maintained at room temperature (Fig. 6).

Cortical content of PGE and PGA was unmeasurable in eight frozen and eight fresh renal specimens from four WKy and four SHR. 17 pairs of WKy and SHR, matched for age, had 24-h urine collections for sodium while eating a standard chow diet. There were no differences in total urine $\mathrm{Na}$ between the normotensive and hypertensive rats.

\section{DISCUSSION}

We have used the Okamoto strain of spontaneously hypertensive rat as an hypertensive model to look for alterations of renal prostaglandin synthesis in one type of experimental essential hypertension (21). This strain of SHR has many features in common with other strains of spontaneously hypertensive rats as well as with human essential hypertension (22). The results of sequential assays of prostaglandin synthetase, in rats of different ages, suggests that renal medullary (microsomal) prostaglandin synthesis increases as hypertension develops perhaps as an homeostatic response to physiologic alterations secondary to the hypertension. It does not seem that renal prostaglandin deficiency can explain the hypertension in this model. Based on our data, renal tissue levels of PGE in snap-frozen medullae appear to be unreliable indicators of increased total synthetic capacity for prostaglandins in the kidney.

Explanation is required for the similar content of PGE in renal medullae from WKy and SHR despite increased microsomal prostaglandin synthetase activity in SHR. There is general agreement that prostaglandins are not stored within cells (23-26). Prostaglandin synthesis is rapid, apparently limited by substrate availability and hence turnover is extensive. If precautions are taken to minimize postmortem synthesis of prostaglandins, tissue levels of PGE are very low by using our assay. These precautions may explain why the values in Table I are much lower than previously reported (5). Therefore if appropriate care is taken to avoid significant postmortem tissue synthesis, tissue levels are quite low and may be a poor reflection of in vivo synthesis (23).

Our data regarding the distribution of the synthetase

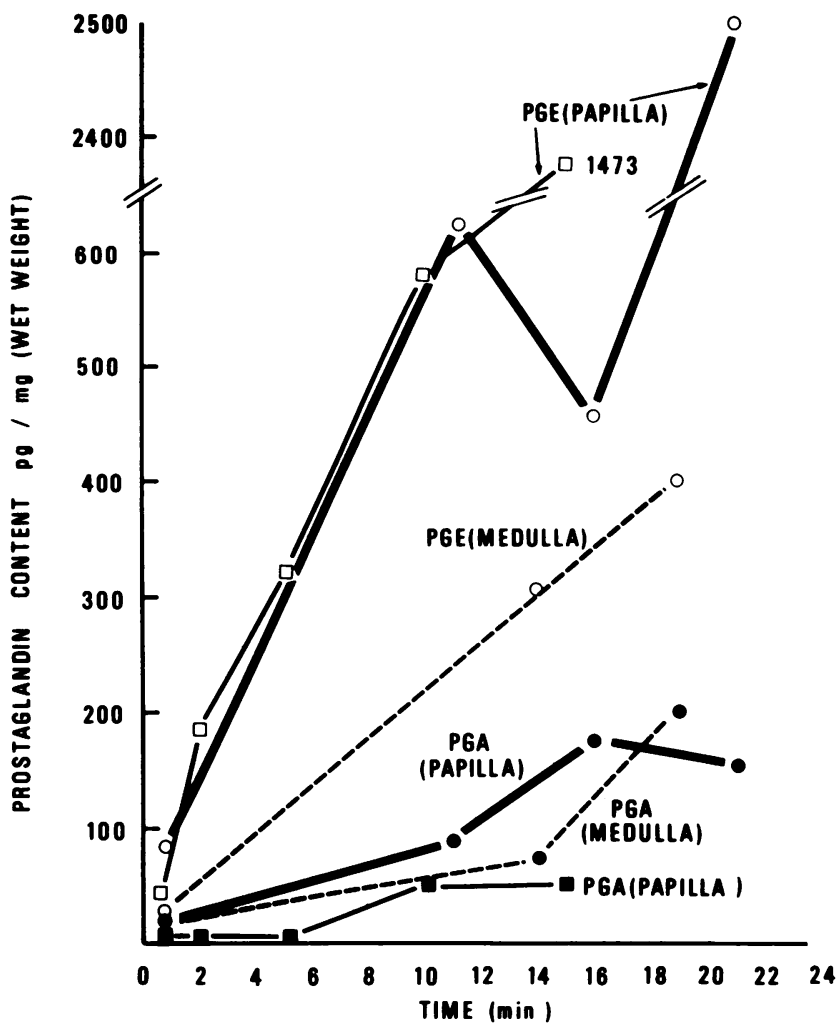

FIGURE 6 Generation of prostaglandins in renal tissue. The base-line samples were obtained less than $45 \mathrm{~s}$ after slaughter of the rat and frozen in liquid nitrogen. The timed samples, up to $21 \mathrm{~min}$, were obtained on fresh medulla and papilla from the opposite kidney which was kept at room temperature. Two separate experiments are indicated: $O$, $\square$, PGE; •, $\mathbf{\square}, \mathrm{PGA}$ ).

system within the kidney confirms the earlier observations of others $(5,19)$ in the rabbit. Our results show a steep gradient of synthetase activity from papilla to cortex emphasizing the necessity to separate medulla from cortex when renal levels of synthetase are measured. The activity of the prostaglandin synthetase in rat papilla and medulla is less than in rabbit kidney papilla and medulla.

Increased synthesis of renal $\mathrm{PGE}_{2}$, in vivo, could possibly modulate the blood pressure and thereby minimize its deleterious effects on the renal vasculature through the vasodilatory and natriuretic properties of $\mathrm{PGE}_{2}$ (6). The potential actions of enhanced $\mathrm{PGF}_{2 a}$ synthesis are more difficult to assess for several reasons. The intrarenal actions of $\mathrm{PGF}_{2 a}$ in the dog may be to increase sodium excretion with minimal effects on blood flow but the doses required are higher than those of $\mathrm{PGE}_{2}$ or $\mathrm{PGA}_{2}$ and its physiologic role is unknown (27, 28). Finally, it should be stressed that the ratios of $\mathrm{PGE}_{2}$ to $\mathrm{PGF}_{2 a}$ produced in vitro are partially dependent on the relative concentrations of arachidonic acid and of co-factors and therefore we do not know if the same 
ratios of $\mathrm{PGE}_{2}$ to $\mathrm{PGF}_{2 a}$ would be found in vivo (29$31)$. Like others $(30,31)$ we have also detected the formation of what appears to be $\mathrm{PGD}_{2}$ (see Fig. 1) by renal microsomes.

Previously, other investigators have concluded that there was increased renal prostaglandin synthesis in response to diverse types of hypertension. Tobian and coworkers have demonstrated decreased osmiophilic granularity in the renal medullary interstitial cells of rats with postsalt (32), Goldblatt (33), and post-Goldblatt (34) forms of hypertension. Muehrcke et al. made similar observations in rats with desoxycorticosterone acetatesalt hypertension (35). Mandal and co-workers have reported similar findings in the species used for the present study, namely the Japanese SHR $(36,37)$. These groups have concluded that decreased granularity was a measure of depleted lipid precursors of prostaglandin production and therefore reflected increased synthesis. Tobian and Azar supported this conclusion by showing enhanced

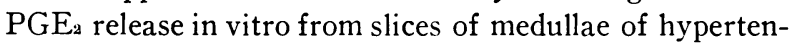
sive rats (38). Recent work has re-enforced these conclusions based on interstitial cell granularity by correlating decreased renal content of $\mathrm{PGF}_{2 \alpha}$ and increased granularity of renal medullary interstitial cells in rabbits after indomethacin administration (39). Sirois and Gagnon (12), who used Goldblatt and SHR models, have reported contrasting results to those of Tobian and the present report. They observed decreased release of $\mathrm{PGE}_{2}$-like material from the renal papilla obtained from the hypertensive animals and incubated for $30 \mathrm{~min}$ in Krebs solution. Two other groups have also reported decreased renal $\mathrm{PGE}_{2}$ synthesis in renal models of hypertension $(10,11)$.

Other workers who have used various bioassays have reported increased tissue levels of PGE-like and PGAlike material in the kidneys of rabbits (8) and rats (7, 40) with Goldblatt hypertension. Zusman et al., by using a RIA for PGA, found greater amounts of PGA in the whole kidneys (unfrozen) of SHR compared to normal wistar rats (9). These results are difficult to interpret since we were unable to detect PGA in SHR renal tissue using different methodology. Grodzinska et al. (41) have published measurements of prostaglandin synthetase on renal cellular extracts of hypertensive animals (uninephrectomized rats with aortic coarctation). They did not separate microsomes from cytosol and the production of prostaglandin end products was measured by bioassay. They noted an initial fall of prostaglandin synthetase at 4 days with an increase at 10 days and normalization of activity at 21 days. They also reported increased tissue content of prostaglandin at all three points of time (41).

Others have taken a different viewpoint regarding renal prostaglandin production and hypertension in the rat $(42,43)$. These workers observed renal vasoconstriction after administration of $\mathrm{PGE}_{2}$ to rats and enhancement of the vasoconstrictor response to sympathetic nerve stimulation. These findings, coupled with the observation that renal 15-hydroxy prostaglandin dehydrogenase decreases in New Zealand genetic hypertensive rats, prompted Armstrong et al. to suggest that increased renal concentration of $\mathrm{PGE}_{2}$ may cause this type of hypertension (43). Pace-Asciak has recently reported that 15-hydroxy prostaglandin dehydrogenase is also decreased in the Japanese SHR (44).

The potential role of prostaglandin synthesis in the control of blood pressure is possibly elucidated by studies in normotensive and hypertensive animals in which prostaglandin production rates have been experimentally altered. The administration of indomethacin, a potent inhibitor of prostaglandin synthetase, acutely raises the blood pressure after intravenous use in normotensive rats (41) and rabbits $(45,46)$ and chronically elevates the blood pressure in normotensive rabbits (47). In Goldblatt rats and rabbits administration of indomethacin elevated blood pressure $(10,48,49)$. In Japanese SHR ranging from 10-38 wk of age acute administration of indomethacin has been reported to increase blood pressure $40 \mathrm{~mm} \mathrm{Hg}$ at $30 \mathrm{~min}$, whereas there were no alterations of BP in 7-8 wk SHR or 23-32 wk WKy. Enhancement of prostaglandin synthesis by the acute administration of arachidonic acid substantially reduced blood pressure (10-60\%) in normal rabbits (46) and in Okamoto SHR (50) ; furthermore this effect was blocked by indomethacin in both experiments. One must be cautious interpreting these results since the indomethacin and the arachidonic acid were given systemically and hence the specific role of the kidney in the systemic response of blood pressure is unknown. It should be noted that Tannenbaum et al. have found that acute infusions of arachidonic acid into the renal artery of normotensive dogs have no effect on systemic blood pressure despite significant acute changes of renal blood flow and sodium excretion (51). Simpson has reported enhanced vasodepressor activity of $\mathrm{PGE}_{2}$ (but not of other vasodilators) in SHR when compared to three normotensive strains of rat (52).

We have been cautious with regard to the PGA2-like end-product of the synthetase reaction. Prevous attempts by other investigators have not demonstrated direct enzymatic production of $\mathrm{PGA}_{2}$ in the kidney (5, $30,31)$. More refined techniques of identification of the $\mathrm{PGA}_{2}$-like spot $\left(\mathrm{R}_{\mathrm{f}}, 0.66\right)$ are required to positively separate 15-keto-13, 14-dihydro $\mathrm{PGE}_{2}$ hydroxy acids, $\mathrm{PGB}_{2}$, and $\mathrm{PGA}_{2}(20)$. Furthermore, our use of glutathione in the incubation mixture for the synthetase

\footnotetext{
${ }^{4}$ Levy, J. Personal communication. 1975. Presented at the prostaglandin conference, Vail, Colo., March 1975.
} 
reaction undoubtedly formed water soluble adducts with PGA and thereby diminished the extraction of PGA into the organic solvent used to spot the silica gel plates (53). Our inability to measure PGA in frozen rat medulla using radioimmunoassay suggests that the radiolabeled end-product with an $R_{\mathbf{r}}$ of 0.66 is not PGA.

\section{ACKNOWLEDGMENTS}

I am grateful to Dr. P. Wong for assistance and advice with the prostaglandin synthetase assay. Dr. John Pike, Upjohn Co., Kalamazoo, Michigan, supplied the unlabeled prostaglandins. Indomethacin was provided by Merck, Sharp and Dohme. This work was supported by the U. S. Public Health Service, the Markle Foundation, and The Vermont Heart Association.

\section{REFERENCES}

1. Muirhead, E. E. 1973. Vasoactive and antihypertensive effects of prostaglandins and other renomedullary lipids. In The Prostaglandins Pharmacological and Therapeutic Advances. M. F. Cuthbert, editor. J. B. Lippincott Company, Philadelphia, Pa. 201-251.

2. Vane, J. R., and J. C. McGiff. 1975. Possible contributions of endogenous prostaglandins to the control of blood pressure. Circ. Res. I (Suppl.) : 36; 68-75.

3. Tobian, L. 1972. A viewpoint concerning the enigma of hypertension. Am. J. Med. 52: 595-609.

4. Lee, J. B. 1973. Renal homeostasis and the hypertensive state: A unifying hypothesis. In The Prostaglandins. P. W. Ramwell, editor. Plenum Publishing Corp., New York. 1: 133-187.

5. Crowshaw, K., and J. C. McGiff. 1973. Prostaglandins in the kidney: A correlative study of their biochemistry and renal function. In Mechanisms of Hypertension. M. P. Sambhi, editor. American Elsevier Publishing Co., Inc., New York. 254-273.

6. McGiff, J. C., and H. D. Itskovitz. 1973. Prostaglandins and the kidney. Circ. Res. 33 : 479-488.

7. Somova, L. 1973. Inhibition of prostaglandin synthesis in the kidneys by aspirinlike drugs. In Advances in the Biosciences 9, Inter. Conf. on Prostaglandins. S. Bergström, editor. Pergamon Press Ltd., Oxford. 335-339.

8. Nekrasova, A. A., R. I. Sokolova, and L. A. Lantsberg. 1973. Prostaglandinlike renal vasodepressor lipids and electrolyte exchange in the kidney. In Advances in the Biosciences 9, Inter. Conf. on Prostaglandins. S. Bergström, editor. Pergamon Press Ltd., Oxford. 307312.

9. Zusman, R. M., B. H. Forman, G. Schneider, B. V. Caldwell, L. Speroff, and P. J. Mulrow. 1973. The effect of chronic sodium loading and sodium restriction on plasma and renal concentrations of prostaglandin A in normal Wistar and spontaneously hypertensive Aoki rats. Clin. Sci. Mol. Med. 45: 325s-329s.

10. Pugsley, D. J., L. J. Beilin, and R. Peto. 1975. Renal prostaglandin synthesis in the Goldblatt hypertensive rat. Circ. Res. I (Suppl.) : 36-37; 81-88.

11. Leary, W. P., J. G. Ledingham, and J. R. Vane. 1974. Impaired prostaglandin release from the kidneys of salt-loaded and hypertensive rats. Prostaglandins. 7: 425-432.

12. Sirois, P., and D. J. Gagnon. 1974. Release of renomedullary prostaglandins in normal and hypertensive rats. Experientia (Basel). 30: 1418-1419.
13. Parkes, D. G., and T. E. Eling. 1974. Characterization of prostaglandin synthetase in guinea pig lung. Isolation of a new prostaglandin derivative from arachidonic acid. Biochemistry. 13: 2598-2604.

14. Flower, R. J., H. S. Cheung, and D. W. Cushman. 1973. Quantitative determination of prostaglandins and malondialdehyde formed by the arachidonic oxygenase (prostaglandin synthetase) system of bovine seminal vesicles. Prostaglandins. 4 : 325-341.

15. Yoshimoto, A., H. Ito, and K. Tomita. 1970. Cofactor requirements of the enzyme synthesizing prostaglandin in bovine seminal vesicles. J. Biochem. (Tokyo). 68: 487-499.

16. Lowry, O. H., N. J. Rosebrough, A. L. Farr, and R. J. Randall. 1951. Protein measurement with the Folin phenol reagent. J. Biol. Chem. 193: 265-275.

17. Dunn, M. J., R. Staley, and M. Harrison. 1976. Prostaglandin production in a cell culture derived from renal medulla. Prostaglandins. 12 : 37-49.

18. Jaffe, B. M., and H. R. Behrman. 1974. Prostaglandins E. A. and F. In Methods of Hormone Radioimmunoassay. B. M. Jaffe and H. R. Behrman, editors. Academic Press, Inc., New York. 19-36.

19. Larsson, C., and E. Änggård. 1973. Regional differences in the formation and metabolism of prostaglandins in the rabbit kidney. Eur. J Pharmacol. 21: 30-36.

20. Pace-Asciak, C. 1975. Activity profiles of prostaglandin 15- and 9-hydroxydehydrogenase and 13-reductase in the developing rat kidney. J. Biol. Chem. 250: 27952800 .

21. Okamoto, K. 1972. In Spontaneous Hypertension; its pathogenesis and complications. K. Okamato, editor. Springer-Verlag, Berlin. 1-8.

22. Dunn, M. J., and R. L. Tannen. In press. Low renin hypertension. In The Physiopathology of Hypertension. J. Genest, E. Koiw, and W. Nowaczynski, editors.

23. Änggård, E., S. O. Bohman, J. E. Griffin, III, C. Larsson, and A. B. Maunsbauch. 1972. Subcellular localization of the prostaglandin system in the rabbit renal papilla. Acta Phy'siol. Scand. 84: 231-246.

24. Christ, E. J., and D. A. van Dorp. 1973. Comparative aspects of prostaglandin biosynthesis in animal tissues. In Advances in the Biosciences 9, Intern. Conf. on Prostaglandins. S. Bergström, editor. Pergamon Press Ltd., Oxford. 35-38.

25. Cohen, F., and B. M. Jaffe. 1973. Production of prostaglandins by cells in vitro: radioimmunoassay measurement of the conversion of arachidonic acid to $\mathrm{PGE}_{2}$ and $\mathrm{PGF}_{2 a}$. Biochem. Biophys. Res. Commun. 55: 724 729.

26. Levine, L. 1972. Prostaglandin production by mouse fibrosarcoma cells in culture: inhibition by indomethacin and aspirin. Biochem. Biophy's. Res. Commun. 47: 888896.

27. Fulgraff, G., and G. Brandenbusch. 1974. Comparison of the effects of the prostaglandins $A_{1}, E_{2}$, and $F_{2 a}$ on kidney function in dogs. Pfluegers Arch. Eur. J. Phy'siol. 349 : 9-17.

28. Fulgraff, G., G. Brandenbusch, and K. Heintze. 1974. Dose response relation of the renal effects of $P_{G A}$, $\mathrm{PGE}_{2}$, and $\mathrm{PGF}_{2 \alpha}$ in dogs. Prostaglandins. 8: 21-30.

29. Duvivier, J., D. Wolf, and C. Heusghem. 1975. Enzymatic properties of prostaglandin synthetase from bovine seminal vesicles. Biochemie. (Paris). 57: 521-528.

30. Blackwell, G. J., R. J. Flower, and J. R. Vane. 1975. Some characteristics of the prostaglandin synthesizing 
system in rabbit kidney microsomes. Biochem. Biophys. Acta. 398: 178-190.

31. Tai, H. H., C. L. Tai, and C. S. Hollander. 1976. Biosynthesis of prostaglandins in rabbit kidney medulla. Properties of prostaglandin synthetase. Biochem. J. $154: 257-264$.

32. Tobian, L., M. Ishii, and M. Duke. 1969. Relationship of cytoplasmic granules in renal papillary interstitial cells to "postsalt" hypertension. J. Lab. Clin. Med. 73: 309-319.

33. Ishii, M., and L. Tobian. 1969. Interstitial cell granules in renal papilla and the solute composition of renal tissue in rats with Goldblatt hypertension. J. Lab. Clin. Med. $74:$ 47-52.

34. Tobian, L., and M. Ishii. 1969. Interstitial cell granules and solutes in renal papilla in post-Goldblatt hypertension. Am. J. Phy'siol. 217: 1699-1702.

35. Muehrcke, R. C., A. K. Mandal, M. Epstein, and F. I. Volini. 1969. Cytoplasmic granularity of the renal medullary interstitial cells in experimental hypertension. $J$. Lab. Clin. Med. 73: 299-308.

36. Mandal, A. K., E. D. Frohlich, K. Chrysant, M. A. Pfeffer, A. Yunice, and J. A. Nordquist. 1974. Ultrastructural analysis of renal papillary interstitial cell of spontaneously hypertensive rats. J. Lab. Clin. Mcd. 83: 256-262.

37. Mandal, A. K., E. D. Frohlich, K. Chrysant, J. Nordquist, M. A. Pfeffer, and M. Clifford. 1975. A morphological study of the renal papillary granule: Analysis in the interstitial cell and in the interstitium. J. Lab. Clin. Med. 85: 120-131.

38. Tobian, L., and S. Azar. 1971. Antihypertensive and other functions of the renal papilla. Trans. Assoc. Am. Phy'sicians. Phila. 84 : 281-288.

39. Comai, K., P. Prose, S. J. Farber, and J. R. Paulsrud. 1974. Correlation of renal medullary prostaglandin content and renal interstitial cell lipid droplets. Prostaglandins. 6 : 375-379.

40. Somova, L. 1971. A study on the vasodepressor lipid isolated from kidneys of hypertensive animals. Nephron. 8: $575-583$.

41. Grodzinska, L., K. Schör, U. Wartner, W. Forster, and R. Gryglewski. 1974. Prostaglandin synthetase activity in the renal medulla of normal and hypertensive rats. Pol. J. Pharmacol. Pharm. 26: 229-235.

42. Malik, K. U., and J. C. McGiff. 1975. Modulation by prostaglandins of adrenergic transmission in the isolated perfused rabbit and rat kidney. Circ. Res. 36: 599609.

43. Armstrong, J. M., G. J. Blackwell, R. J. Flower, J. C. McGiff, K. Mullane, and J. Vane. 1975. Genetic hypertension in rats is accompanied by a defect in renal prostaglandin catabolism. Nature (Lond.). 260: 582586.

44. Pace-Asciak, C. R. 1976. Ontogenetic differences in prostaglandin catabolism between kidneys from normotensive and hypertensive rats. Fed. Proc. 35: 223. (Abstr.)

45. Davis, H. A., and E. W. Horton. 1972. Output of prostaglandins from the rabbit kidney, its increase on renal nerve stimulation and its inhibition by indomethacin. Br. J. Pharmacol. 46: 658-675.

46. Larsson, C., and E. Änggård. 1973. Arachidonic acid lowers and indomethacin increases the blood pressure of the rabbit. J. Pharm. Pharmacol. 25: 653-655.

47. Colina-Chourio, J., J. C. McGiff, and A. Nasjletti. 1975. Development of high blood pressure following inhibition of prostaglandin synthesis. Fed. Proc. 34: 368. (Abstr.)

48. Romero, J. C., J. J. Aguilo, and C. G. Strong. 1975. Effects of indomethacin blockade of prostaglandin synthesis in rabbit renovascular hypertension. Circulation. II (Suppl.): 51-52; 124. (Abstr.)

49. Schölkens, B. A., and R. Steinbach. 1975. Increase of experimental hypertension following inhibition of prostaglandin biosynthesis. Arch. Int. Pharmacodyn. Ther. 214: 328-334.

50. Cohen, M., J. Sztokalo, and E. Hinsch. 1973. The antihypertensive action of arachidonic acid in the spontaneous hypertensive rat and its antagonism by antiinflammatory agents. Life Sci. 13: 317-325.

51. Tannenbaum, J., J. A. Splawinski, J. A. Oates, and A. S. Nies. 1975. Enhanced renal prostaglandin production in the dog. I. Effects on renal function. Circ. Res. 36: 197-203.

52. Simpson, L. L. 1974. The effect of prostaglandin $E_{2}$ on the arterial blood pressure of normotensive and spontaneously hypertensive rats. Br. J. Pharmacol. 51: 559564.

53. Ham, E. A., H. G. Oien, E. H. Ulm, and F. A. Kuehl, Jr. 1975. The reaction of $\mathrm{PGA}_{1}$ with sulfhydryl groups; a component in the binding of A-type prostaglandins to proteins. Prostaglandins. 10: 217-229. 